\title{
A IMPORTÂNCIA DA SISTEMATIZAÇÃO DE UM BANCO DE DADOS GEOGRÁFICOS VETORIAIS DA DIVISÃO POLÍTICO-ADMINISTRATIVA DO MUNICÍPIO DE DOM PEDRITO/RS PARA USOS AMBIENTAIS E AGROPECUÁRIOS
}

\author{
THE IMPORTANCE OF A VECTOR GEOGRAPHIC DATABASE SYSTEMATIZATION \\ OF THE POLITICAL-ADMINISTRATIVE DIVISION OF THE MUNICIPALITY OF \\ DOM PEDRITO / RS TO ENVIRONMENTAL AND AGRICULTURAL USES
}

\author{
Shirley Grazieli da Silva Nascimento 1 \\ Júlio César Cordeiro da Silva ${ }^{2}$ \\ Daniel Hanke \\ Mariana Rockenbach de Ávila ${ }^{4}$ \\ Bruno Scorsatto Menegon ${ }^{5}$
}

RESUMO: O presente trabalho apresenta a sistematização de um banco de dados com arquivos geoespacias vetoriais da divisão administrativa do município de Dom Pedrito/RS, a partir dos mapas base do IBGE. A metodologia aplicada para a sistematização de um banco de dados vetoriais consiste na aquisição dos arquivos Shapefiles no banco de dados do IBGE, utilizando o software QGIS 2.14 para a manipulação vetorial e a elaboração de mapas, abrangendo: 0 limite municipal, limites intramunicipais, manchas urbanas, todos ajustados (quando necessário) no sistema de projeção UTM (Zona 21S) e Datum Sirgas 2000. Os resultados e mapas obtidos contribuem para a discussão da aplicabilidade de ferramentas e a necessidade de aplicação de um SIG em diferentes casos e objetivos. O município de Dom Pedrito é composto por divisões territoriais chamadas de Distritos e Subdistritos, estabelecidas e constituídas pela Lei Orgânica municipal datada de 02 de abril de 1990. Essa divisão muitas vezes gera dúvidas quanto a real localização espacial destas unidades distritais. Propõe-se eficiência e exatidão nos processos de localização de propriedades tanto em iniciativas públicas como em assessorias privadas. Através dos resultados obtidos conclui-se que este trabalho possibilitou a estruturação da divisão administrativa do município em estudo. Dessa maneira, análises rápidas e com grande precisão serão viabilizadas em áreas de interesse para aplicação de políticas públicas ou atividades privadas.

Palavras-chave: Divisão distrital, Propriedades, Mapas, Sistema de informação georreferenciadas.

\footnotetext{
1 https://orcid.org/0000-0001-6888-9967

2 https://orcid.org/0000-0002-6132-1452

3 https://orcid.org/0000-0001-9546-8527

4 https://orcid.org/0000-0001-6278-7513

5 https://orcid.org/0000-0003-3184-9173

ABSTRACT: The present paper shows a database systematization with geospatial vector files from the administrative division of the municipality of Dom Pedrito / RS, based on the IBGE base maps. The methodology applied for systematizing consists in Shapefiles acquisition from IBGE database, using the QGIS 2.14 software for vector manipulation and map making, covering: the municipality dominion limit, intra-municipal limits, spots urban, all adjusted (when necessary) in the UTM projection system (Zona 21S) and Datum Sirgas 2000. The results and maps obtained contribute to the applicability of tools and the need to apply a GIS in different cases and objectives. The municipality of Dom Pedrito is composed of territorial divisions called Districts and Subdistricts, established and constituted by the municipal Organic Law dated April 2, 1990. This division often raises doubts about the real spatial location of these district units. Efficiency and accuracy are proposed in the processes of locating properties both in public initiatives and in private consultancy. Through the results obtained, it can be concluded that this work made it possible to structure the administrative division of the municipality under study. In this way, rapid and highly accurate analyzes will be made possible in areas of interest for the application of public policies or private activities.

Keywords: District division, Properties, Maps, Georeferenced information system. 


\section{INTRODUÇÃO}

Dentre as várias formas de divisão e demarcação territorial entre países, a divisão política do mundo (Raffastin, 1993) constitui um dos formatos mais marcantes de regionalização da atualidade. Neste contexto, o mundo se apresenta dividido por países soberanos e independentes entre si, que por sua vez se dividem em estados, distritos, condados, comarcas, províncias, vilas, regiões, departamentos, sendo que independente de nome ou função atribuída a divisão territorial (Benko, 2001), este sistema é amplamente adotado no contexto político-administrativo da atualidade (Oliveira, 2006).

Entretanto, todos estes formatos de divisão citados anteriormente, convergem para um único objetivo, que é oportunizar o controle administrativo, sendo assim subdividida a responsabilidade de fiscalizar e organizar político-administrativamente estes territórios. Analisando as divisões territoriais dentro de um estado como parte integrante de um país, estas podem cumprir com diversas finalidades tais como a autonomia administrativa, jurisdição por parte da justiça entre outras.

O Brasil no presente se apresenta subdividido dentro de um contexto político e administrativo em 27 unidades federativas autônomas entre si, sendo 26 estados e um distrito federal. Todos possuem autonomia governamental e administrativa sem interferência de outros estados da federação (Kerbauy, 2005; Piquet; Almeida, 2008). Como componente de uma das 27 unidades federativas do Brasil, o estado do Rio Grande do Sul possui 497 municípios, que são dotados de autonomia política, administrativa e financeira, sendo que o territó- rio de cada município poderá ser dividido em distritos e subdistritos, criados, organizados e extintos por lei municipal, observada a legislação estadual.

O município de Dom Pedrito é parte componente de um dos 497 municípios do Estado do Rio Grande do Sul. Atualmente o território do Município de Dom Pedrito compreende uma área de 5.190,238 km² (IBGE, 2017). A administração municipal entrega uma série de serviços à comunidade, dentre eles os serviços ambientais e de gestão do seu território. Para que estes sejam prestados com eficiência e estejam em permanente atualização, se faz necessário o uso de tecnologias que auxiliem neste processo.

A ideia central deste trabalho foi criar um banco de dados geográficos vetoriais para a utilização na gestão espacial do território do município de Dom Pedrito, onde em sua bibliográfica faz-se uma revisão da literatura no que diz respeito a Sistema de Informações Geográficas (SIG), passando por suas características, formatos e utilização da tecnologia, conceitos básicos de Banco de Dados Geográficos como ponto central de um sistema SIG, suas aplicações e funcionalidades.

O Sistema de Informações Geográficas se trata de uma ferramenta que facilita a análise, gestão ou representação de espaços geográficos e dos fenômenos que nele ocorrem. Um Banco de Dados Geográficos caracteriza-se por possuir uma coleção de mapas e informações agrupadas em formato digital. Como o Banco de Dados trata de feições da superfície terrestre, ele compreende dois elementos: um Banco de Dados Espacial descrevendo a geografia em forma e posição das feições e, um Banco de 
Dados de Atributos descrevendo as características ou qualidades dessas feições (Vieira; Tagliani, 2001).

Contudo este trabalho pode proporcionar um novo formato de planejamento dentro do universo administrativo local, possibilitando a visualização espacial das mais diversas áreas de atuação da gestão municipal.

O presente trabalho objetivou sistematizar um banco de dados com arquivos geoespacias vetoriais da divisão administrativa do município de Dom Pedrito/RS, a partir dos mapas base do IBGE e constituir uma base de dados geoespaciais para utilização tanto por entes públicos como privados no município, com intuito de auxiliar na organização da prestação de serviços ambientais e agropecuários no município.

\section{SISTEMAS DE INFORMAÇÃO GEOGRÁ- FICA (SIG)}

O termo Sistemas de Informação Geográfica (SIG) é aplicado para sistemas que realizam o tratamento computacional de dados geográficos e recuperam informações não apenas com base em suas características alfanuméricas, mas também através de sua localização espacial; oferecem ao administrador (urbanista, planejador, engenheiro) uma visão inédita de seu ambiente de trabalho, em que todas as informações disponíveis sobre um determinado assunto estão ao seu alcance, inter-relacionadas com base no que lhes é fundamentalmente comum a localização geográfica (Davis; Câmara, 2001).

Devido a sua ampla gama de aplicações, que inclui temas como agricultura, floresta, cartografia, cadastro urbano e re- des de concessionárias (água, energia e telefonia), há pelo menos três grandes maneiras de utilizar um SIG: a) ferramenta para produção de mapas; b) como suporte para análise espacial de fenômenos; c) banco de dados geográficos, com funções de armazenamento e recuperação de informação espacial. Estas três visões do SIG são antes convergentes que conflitantes e refletem a importância relativa do tratamento da informação geográfica dentro de uma instituição (Câmara, 1995).

O SIG - Sistema de Informação Geográfica, segundo Aronoff (1989), dentro de seu contexto é compreendido, como um conjunto de procedimentos específicos, sendo manuais ou automatizados, aplicados com o objetivo de armazenar e manipular as informações georreferenciadas, proporcionando a avaliação de condições ambientais com precisão e eficiência, na coleta e organização dos dados (Xavier da Silva, 2001).

Sicherman (1981) afirma que o conjunto de funcionalidades disponibilizados por um SIG é que irão fornecer aos profissionais da área de geoprocessamento, capacidades avançadas quanto a utilização de dados geoespaciais. Conjunto de funções automatizadas, que fornecem aos profissionais, capacidades avançadas de armazenamento, acesso, manipulação e visualização de informação georreferenciada. Nesse sentido, surge a reflexão de que além de um SIG, é preciso ter profissionais capacitados com conhecimentos específicos na área de geoprocessamento, para que se possa usufruir plenamente das funcionalidades desta ferramenta.

Para Marble, (1984) um SIG pode ser definido como um "sistema voltado à aqui- 
sição, análise, armazenamento, manipulação e apresentação de informações referenciadas espacialmente”. Os SIG fornecem uma estrutura que permite a aquisição e organização de dados de natureza espacial e informação relacionada para que estes possam ser visualizados e analisados (ESRI, 2015).

Segundo Câmara (1995) as definições de SIG refletem, cada uma à sua maneira, a multiplicidade de usos e visões possíveis desta tecnologia e apontam para uma perspectiva interdisciplinar de sua utilização. Para Moura (2000, p. 24), os SIGs são essenciais no processo de planejamento, pois, contribuem em muito na sistematização de dados, já que ao buscar formas de trabalhar com as relações espaciais ou lógicas, tende a evoluir do descritivo para o prognóstico.

Um SIG é composto por um conjunto de várias "ferramentas" especificas e especializadas em adquirir, armazenar, recuperar, transformar e produzir informações gerando dados geoespaciais. Esses dados geográficos através de seus atributos representam objetos do mundo real quanto ao seu posicionamento, tendo como referência um sistema de coordenadas geográficas. Estes atributos carregam informações não aparentes como (cor, $\mathrm{pH}$, custo, incidência de pragas, etc) (Câmara; Ortiz, 1998).

Portanto, um SIIG pode ser utilizado em estudos relativos ao meio ambiente e recursos naturais, na pesquisa da previsão de determinados fenômenos ou no apoio a decisões de planejamento, considerando a concepção de que os dados armazenados representam um modelo do mundo real (Burrough, 1986).
Contudo podemos destacar a importância e os ganhos na utilização de um sistema de informações geográficas em relação aos métodos tradicionais de análise espacial, enfatizando a eficiência na tomada de decisões sobre uma base técnica e não subjetiva, proporcionando a racionalização no uso dos recursos disponíveis.

\section{UTILIZAÇÃO DE DADOS GEOGRÁFI- COS NO PLANEJAMENTO DE ATIVIDA- DES}

Os serviços públicos podem ser melhor planejados, integrando-se informações de origens, tipos e formatos diversos em análise de elevado grau de complexidade (Calkins, 1992).

Planejamento é um termo que envolve conceitos bastante amplos. Pode ser visto como teoria, como processo, como sistema ou como instrumento aplicável a vários tipos de níveis de atividade humana, com objetivos variados que vão desde a alteração estrutural da sociedade até simples composição de programas. Pode-se assim definir planejamento como a aplicação racional do conhecimento do homem ao processo de tomada de decisões para conseguir uma ótima utilização dos recursos, a fim de obter o máximo de benefícios para a coletividade (Santos; Nascimento, 1992).

Neste contexto os sistemas de informação geográfica (SIG) representam uma ferramenta extremamente útil para os propósitos do planejamento municipal. Por reunirem um extenso conjunto de aplicativos, para coletar, armazenar, recuperar e transformar e representar visualmente dados espaciais e também dados estatísticos ou textuais a eles relacionados, os SIG representam um grande passo no sentido de 
uma maior racionalização no planejamento e no gerenciamento de recursos no rol de atividades de administrações municipais (Weber; Hasenack, 1997).

Para Amorim et al. (2009) a constante evolução tecnológica das empresas do setor privado motiva a população a exigir uma modernização no setor público. Apesar da realidade financeira dos municípios de pequeno e médio porte, muitas vezes, não permitir o investimento em novas tecnologias para o apoio ao planejamento da gestão administrativa, "se faz inevitável empreender processos de modernização das administrações, otimizando seu rendimento para melhor servir as necessidades da sociedade” (Rosés, 2004). Também deve ser abordado de forma enfática, a utilização de geotecnologias dentro do contesto social e produtivo das pequenas propriedades rurais, as quais tem um papel fundamental no tocante a fixação das famílias no campo e a produção de alimentos de forma sustentável.

A espacialização de fenômenos e dados georeferenciados, pode facilitar a gestão do território, e é de grande importância na elaboração de políticas públicas, sendo que o mesmo permite identificar no campo visual a resposta a perguntas como onde e por que ocorrem tais fenômenos e de que forma atuar para corrigi-los ou ainda prioriza os locais que sofrerão interferências.

Dentre os métodos e procedimentos que podem ser utilizados como ferramenta de apoio a políticas públicas voltadas para a agricultura familiar em ambiente SIG, incluem a observação e aquisição de dados geoespaciais em campo, através de equipamentos que permitem o cálculo de posicionamento por satélite e a aplicação de questionários para obtenção de dados socioeconômicos da população assistida pelos possíveis programas oferecidos pela administração municipal para este nicho de atividade (Rangel Junior; De Sousa, 2013).

A maioria dos SIG oferece muitos recursos que racionalmente usados permitem obter visões muito particulares do espaço analisado, impossíveis de perceber in loco pelo mais experiente dos observadores. Não existem fórmulas prontas para análises em SIG no ambiente urbano, tampouco sistemas ou dados padronizados para essas análises. Cada município pode e deve desenvolver suas próprias aplicações para resolver os problemas locais mais importantes no período que julgar adequado, levando em conta os recursos humanos e financeiros disponíveis (Rodrigues; Vilaça, 1994).

\section{METODOLOGIA}

\section{ÁREA DE ESTUDO}

O município de Dom Pedrito está localizado na mesorregião do sudoeste Riograndense e na microrregião da Campanha Meridional, situado na região hidrográfica do Uruguai e na bacia hidrográfica do Rio Santa Maria (Figura 1).

Dom Pedrito é um dos cinco municípios que integram a microrregião da campanha meridional, mais precisamente entre os municípios de Bagé, Lavras do Sul, São Gabriel, Rosário do Sul e Santana do Livramento. O limite Norte do município se faz com as cidades de Rosário do Sul, São Gabriel e Lavras do Sul, ao Leste com Bagé, ao Sul com a cidade de Rivera República Oriental do Uruguai, e finalmente ao Oeste com Santana do Livramento.

Este município, essencialmente agríco- 


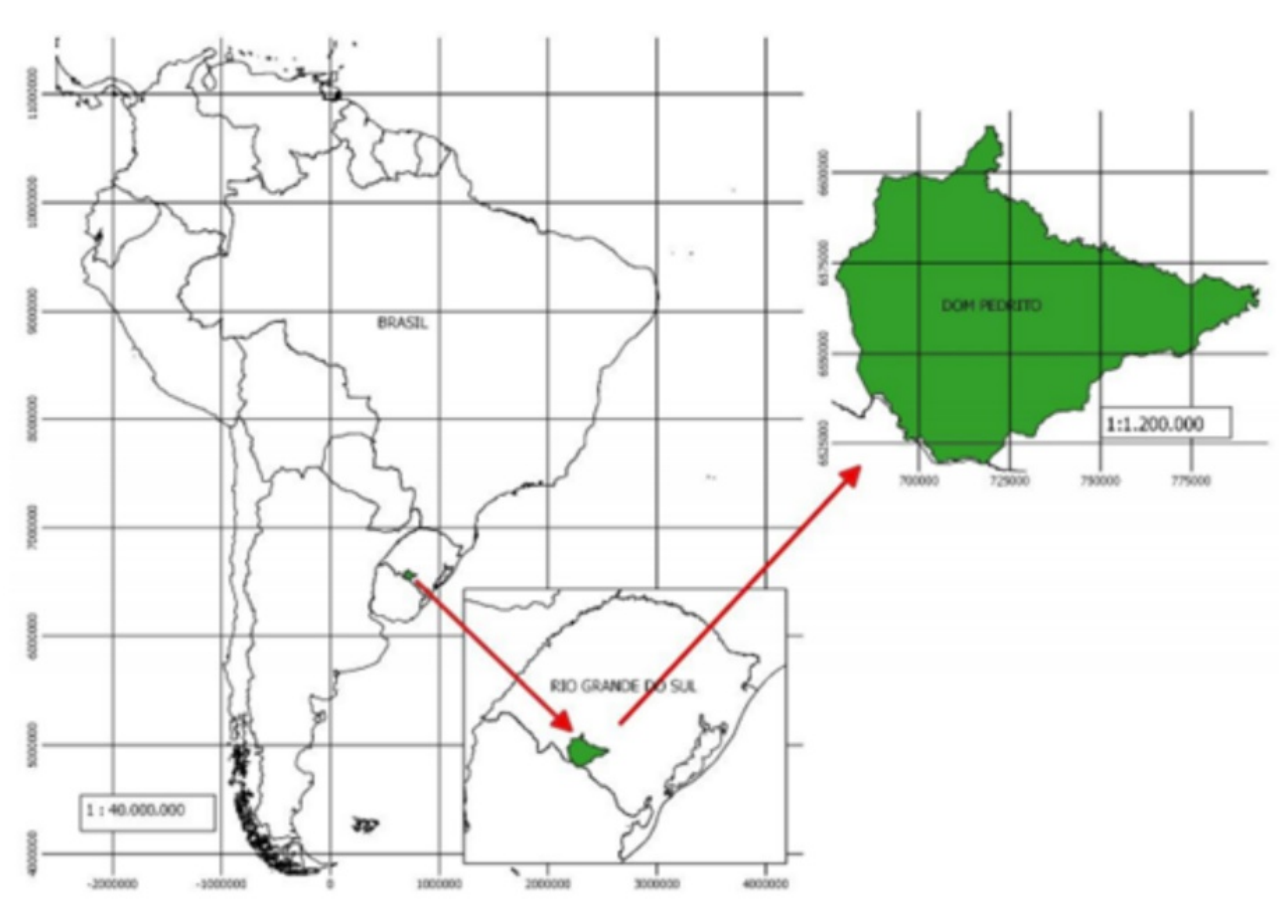

Figura 1: Mapa de localização do município de Dom Pedrito/RS. O mapa 1 apresenta a localização espacial do município em relação a América do Sul, Brasil e o estado do Rio Grande do Sul. Fonte: Elaborado pelos autores (2019).

la, possui sua renda oriunda basicamente do agronegócio. Dá-se destaque as culturas da soja, arroz e uva, produção agropecuária, e a produção agrícola familiar. O município apresenta uma área territorial de $5.190,238 \mathrm{~km}^{2}$, dados oriundos do último Censo (IBGE, 2018; Nascimento, et al., 2018).

ESTRUTURA ATUAL DA DIVISÃO POLÍTICO-ADMINISTRATIVA DO MUNICÍPIO DE DOM PEDRITO.

Conforme Lei Orgânica do município de Dom Pedrito de 02 de abril de 1990, alterada por Emenda datada de 21/11/2000, sua subdivisão está estabelecida em dois distritos. O primeiro distrito que, tendo por sede a cidade de Dom Pedrito, compreende cinco subdistritos: $1^{\circ}$ Subdistrito denominado Sede; $2^{\circ}$ Caveiras; $3^{\circ}$, Vacaiquá; $4^{\circ}$ Ponche Verde; $5^{\circ}$ Fontouras. O segundo distrito denominado Torquato Severo, tem por sede a Vila de São Sebastião (LEI OR-
GÂNICA MUNICIPAL DE DOM PEDRITO - RS, 1990).

A subdivisão do município ocorre em Distritos e Subdistritos, sendo uma importante referência espacial para a regionalização local. No ano de 1946, o cartógrafo Hans Augusto Thofehrn, professor da área de Geografia da UFRGS, Instituto de Geociências, Departamento de Geodésia, elaborou um mapa cartográfico da divisão político-administrativa do município de Dom Pedrito, organizado na administração de A. Coutinho da Rocha.

\section{AQUISIÇÃO E ORGANIZAÇÃO DOS DA- DOS}

A metodologia utilizada para a sistematização da base de dados vetoriais se deu através da aquisição dos Shapefiles através do site Instituto Brasileiro de Geografia e Estatística (IBGE), abrangendo: a) o limite municipal; b) limites intramunicipais e c) manchas urbanas, todos ajustados (quando necessário) no sistema de projeção UTM (Zona 21S) e Datum Sirgas 2000.

As metas quanto à formação do Banco de Dados propuseram caracterizar determinado tipo de informação tendo como base outros elementospré-existentes. Para a obtenção dos arquivos vetoriais que com- 
põe o banco de dados geográficos da divisão político administrativa do municipio de Dom Pedrito, foi realizado o download dos arquivos em formato Shapefile no site do IBGE da área de Geociências, ou seja, na página do site do IBGE.

O processo de aquisição das bases vetoriais foi realizado através de downloads, sendo que cada arquivo de é acompanhado de suas extensões compactadas em formato Zip. A partir da aquisição dos arquivos vetoriais da divisão político-administrativa do município de Dom Pedrito no site do IBGE, os mesmos foram processados no software de geoprocessamento Quantum GIS (QGIS 2.14), originando os mapas distritais de localização e divisão do município, no sistema de projeção de coordenadas UTM Zona 21 Sul, Datum Sirgas 2000.

A espacialização dos limites municipais permite destacar situações que auxiliam no planejamento, tanto no sentido de promover o desenvolvimento quanto o de medidas de intervenção, exemplo: a manutenção de estradas para escoamento da produção agropecuária, o potencial turístico localizado no interior do município, elaboração de pesquisas com mensuração e localização espacial de resultados.

\section{RESULTADOS E DISCUSSÃO}

\section{SISTEMATIZAÇÃO DO BANCO DE DA- DOS COM ARQUIVOS VETORIAIS GEO- ESPACIAIS}

Como exemplo do uso de geotecnologias nos processos de planejamento e tomada de decisão em âmbito administrativo municipal, podemos destacar o trabalho realizado por Vieira; Tagliani (2001), no município de Capão do Leão - RS, cujos seus resultados foram obtenção de vários mapas georreferenciados, em formato digital, que fazem parte do Banco de Dados Geográfico, que compõem a base física referente ao município de Capão do Leão.

A sistematização deste Banco de Dados de arquivos vetoriais do município de Dom Pedrito, proporcionou uma maior agilidade na elaboração de mapas temáticos e na localização de propriedades rurais, nos trabalhos desenvolvidos pelo Departamento de Meio Ambiente de Dom Pedrito. Sua base previamente desmembrada contendo informações de outros municípios como se encontra no banco de dados do IBGE, faz com que se tenha um ganho no campo da precisão e visualização das informações necessárias para a execução de cada trabalho.

A disposição dos arquivos dentro do BDG, também chamado de Banco de Dados Geográficos, é composta por feições do tipo polígono. Estes polígonos representam a geometria de cada localidade Distrito, Subdistrito que também carrega em sua tabela de atributos importantes informações como nome e área em $\mathrm{km}^{2}$. Dentre as bases que compõe o Banco de Dados Vetoriais, podemos destacar os seguintes mapas temáticos.

\section{MAPA DO $1^{\circ}$ SUBDISTRITO SEDE}

$\mathrm{O} 1^{\circ}$ Subdistrito denominado Sede, está localizado na porção Norte do município de Dom Pedrito, fazendo limite ao norte com o município de Lavras do Sul, ao Leste com o Arroio Taquarembó, ao Sul com as estradas municipais DP 310, 445, 205, e ao Oeste com estrada municipal DP 160 e Rio Santa Maria (Figura 2).

Este distrito possui como principal característica a localização do $1^{\circ}$ Distrito que 


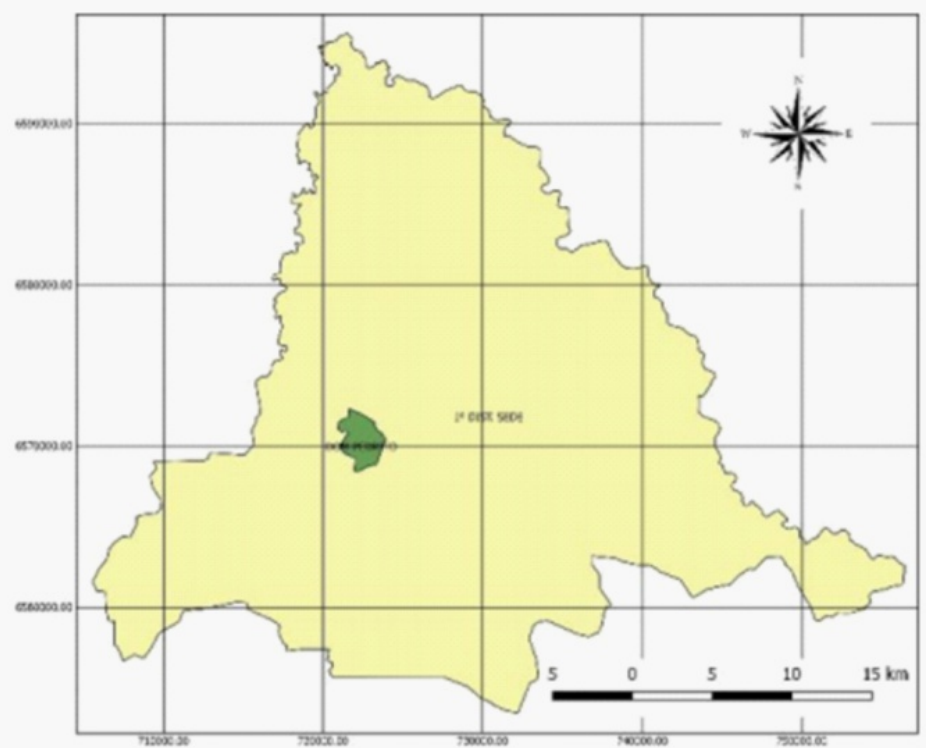

Figura 2: Mapa do $1^{\circ}$ Distrito - Sede.

Fonte: Elaborado pelos autores (2019).

tem por se-

de a cidade de Dom Pedrito.

MAPA DO $2^{\circ}$ SUBDISTRITO CAVEIRAS E MAPA DO $3^{\circ}$ SUBDISTRITO VACAIQUÁ

$\mathrm{O} 2^{\circ}$ Subdistrito denominado Caveiras, está localizado na porção Noroeste do município de Dom Pedrito, fazendo limite ao Norte com os municípios de Rosário do Sul e São Gabriel, ao Leste com o subdistrito Sede, delimitado pelo Rio Santa Maria, ao Sul com a estrada municipal DP 070, e ao Oeste com o município de Santa-

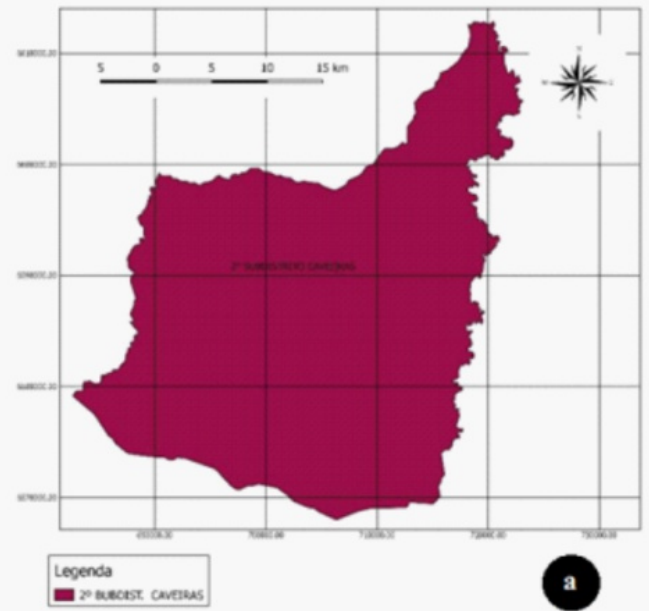

2017).

na do Livramento divisa esta delimitada pelo Rio Santa Maria, ao Sul com a estrada municipal DP 070, e ao Oeste com o município de Santana do Livramento divisa esta delimitada pelo Rio Ibicuí da Armada (Figura 3a).

O subdistrito de Caveiras tem grande importância econômica e social para o município, por sediar dois assentamentos da reforma agrária, Alto Alegre com 20 famílias e Vista Nova com 42 famílias (INCRA,

O $3^{\circ}$ Subdistrito denominado Vacaiquá, está localizado na porção Sudoeste do município de Dom Pedrito, fazendo limite ao norte com o subdistrito de Caveiras delimitado pela DP 070, ao Leste com os subdistritos de Ponche Verde e Sede, delimitado pelas estradas municipais DP 050, 165, 310 e 160, ao Oeste com o município de Santana do Livramento e República Oriental do Uruguai, delimitados pelo Rio Upamaroti. (Figura 3b)

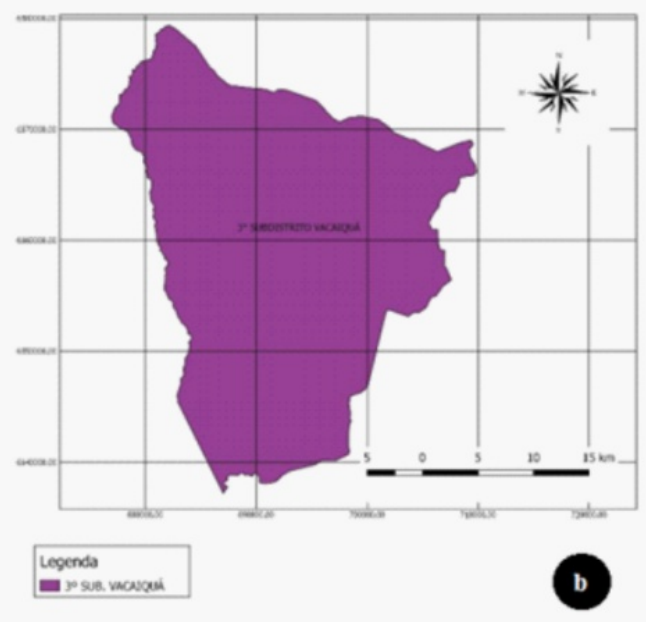

Figura 3: Mapa do a) $2^{\circ}$ Subdistrito Caveiras e b) $3^{\circ}$ Subdistrito Vacaiquá

Fonte: Elaborado pelos autores (2019). 
MAPA DO $4^{\circ}$ SUBDISTRITO PONCHE VERDE E MAPA DO $5^{\circ}$ SUBDISTRITO FONTOURAS

O $4^{\circ}$ Subdistrito denominado Ponche Verde, está localizado ao Sul do município de Dom Pedrito, fazendo limite ao Norte com o subdistrito Sede, ao Sul com República Oriental do Uruguai, ao Leste com o subdistrito de Fontouras, e ao Oeste com o subdistrito de Vacaiquá. (Figura 6a).

O subdistrito de Ponche Verde tem grande importância econômica e social para o município, por sediar dois assentamentos da reforma agrária, Alto Alegre com 20 famílias e Vista Nova com 42 famílias (INCRA, 2017).

O $5^{\circ}$ Subdistrito denominado Fontouras, está localizado ao Sudeste do município de Dom Pedrito, fazendo limite ao Norte com o subdistrito Sede, ao Sul com o município de Bagé, ao Leste com o $2^{\circ}$ Distrito Torquato Severo, e ao Oeste com o subdistrito de Ponche Verde (Figura 4b).

MAPA DO $2^{\circ}$ DISTRITO TORQUATO SEVERO

O $2^{\circ}$ Distrito denominado Torquato Se-

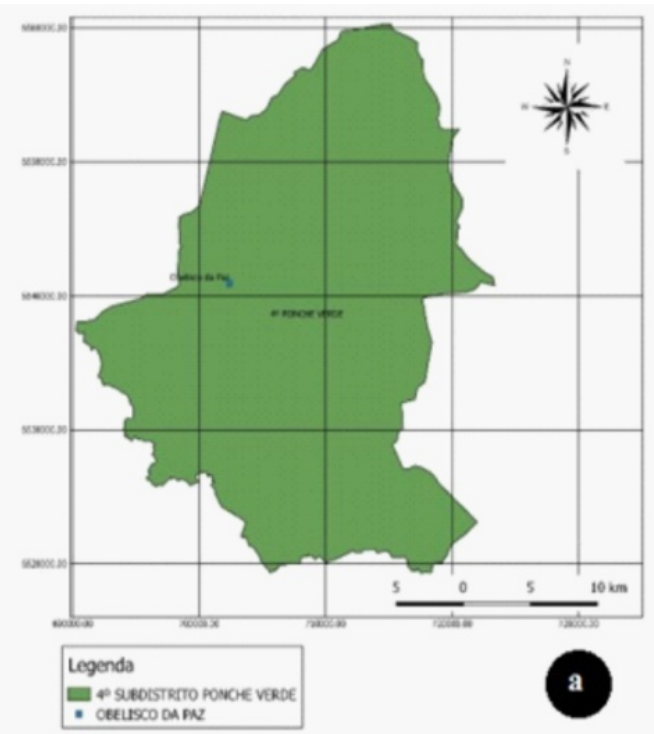

vero, está localizado ao Leste do município de Dom Pedrito, fazendo limite ao Norte com o município de Lavras do Sul, ao Sul e Leste com o município de Bagé, e ao Oeste com os subdistritos de Fontouras e Sede (Figura 5).

Este distrito possui como principal característica a localização da Vila de São Sebastiao e a Estação Ferroviária de São Sebastião.

\section{ESTREITANDO A COMUNICAÇÃO COM A BASE DE DADOS: FORMAS DE ACES- SO AO BANCO DE DADOS}

$\mathrm{O}$ acesso a base de dados pode ser feito através do próprio banco de dados do IBGE em sua página na internet, porém estes arquivos estarão em modo conjunto, ou seja, agrupados juntamente com as informações de todos os municípios do Rio Grande do Sul. A base de dados alvo deste trabalho será disponibilizada já com os dados do município de Dom Pedrito individualizados sendo eles: área do município, áreas distritais e manchas urbanas, em formato (Shapefile) desenvolvido pela empresa Esri e amplamente utilizado por profissionais da área de geoprocessamento em softwares

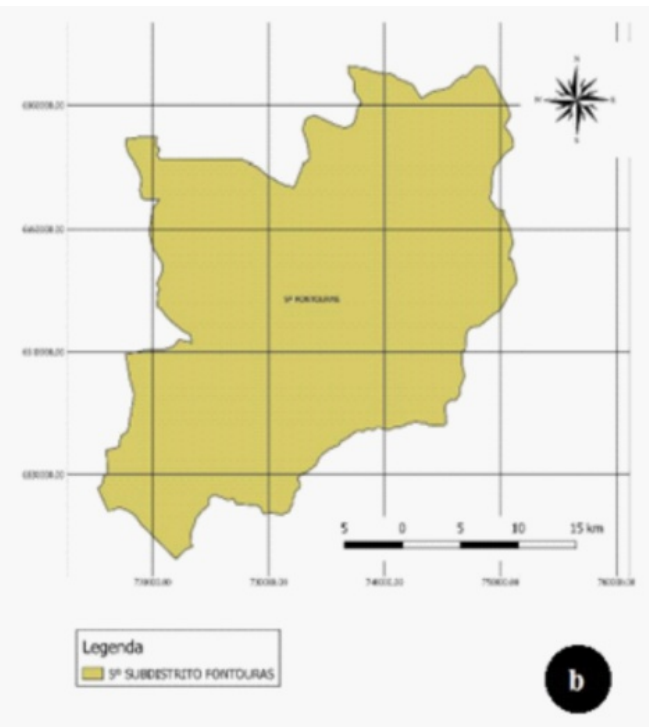

Figura 4: Mapa do a) $4^{\circ}$ Subdistrito Ponche Verde e b) Mapa do $5^{\circ}$ Subdistrito Fontouras. Fonte: Elaborado pelos autores (2019). 


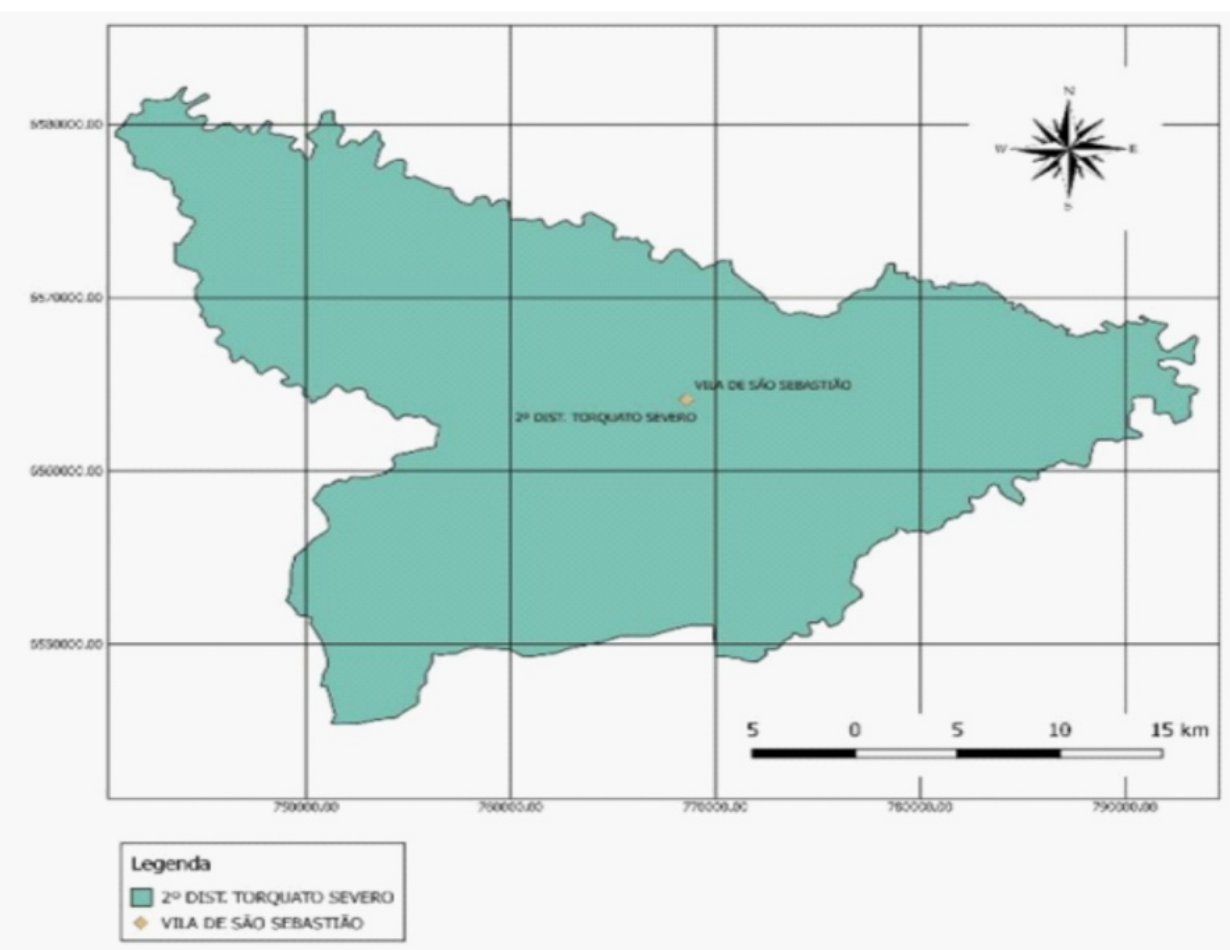

Figura 5: Mapa do $2^{\circ}$ Distrito Torquato Severo.

Fonte: Elaborado pelos autores (2019).

de SIG, eno

formato (KML) Keyhole Markup Language, que foi desenvolvido para o uso com Google Earth.

Os arquivos podem ser copiados em CD ou pendrive, os shapefiles se encontram compactados em formato Zip com suas extensões, dbf, prj, qpj, shp e shx. Os arquivos KML estão nomeados conforme sua característica individual. Estes arquivos estão disponíveis no Departamento de Meio Ambiente do município de Dom Pedrito, e posteriormente será discutido a possibilidade de disponibilizá-los na página do município em seu site na internet.

\section{CONSIDERAÇÕES FINAIS}

A visualização do posicionamento geográfico permitiu a fácil compreensão das análises, atributos, resultados e distribuição espacial qualitativa e quantitativa, possibilitando uma clara apresentação dos objetivos e das proporcionalidades a serem aplicadas.

Esta ferramenta de geoprocessamento será utilizada nos processos de tomada de decisão em relação as questões ambientais e agropecuárias, sendo que a mesma permite ser pontual no lançamento das informações, e ter a amplitude de elementos que podem contribuir para uma gestão territorial eficiente pautada no tripé da sustentabilidade. O banco de dados geográfico vetorial apresenta-se como peça essencial para a realização de trabalhos no âmbito da gestão pública, possibilitando a alimentação constante de informações.

\section{REFERÊNCIAS}

ÂMARA, G., ORTIZ, M. J. Sistemas de informação geográfica para aplicações ambientais e cadastrais: uma visão geral.

Anais... In: Congresso Brasileiro de Engenharia Agrícola. 1998. p. 59-82.

AMORIM, A.; DE SOUZA, G.B.; YAMASHITA, M.C.F. Cadastro técnico multifinalitário via internet: um importante instrumento de apoio ao planejamento municipal. Revista Brasileira de Cartografia, v. 60, n. 2, 2009.

ARONOFF, S. Geographic information systems: a management perspective. Ottawa: DL Publications, 1989. 249p.

BENKO, G. A recomposição dos espaços.

Revista Internacional de Desenvolvi- 
mento Local. Vol. 1, N. 2, p. 7-12, Mar. 2001.

\section{BURROUGH, A. Principles of geo-} graphical information systems for land resources assessment. 1986.

CALKINS, H. W. 1992. GIS and public policy. In: Maguire, D. J., Goodchild, M. F., Rhind, D. W. 1992. Geographical informations systems. Principles and applications. Longmam Scientific \& Techinical, New York. 327.p.

CÂMARA, G. Modelos, linguagens e arquiteturas para bancos de dados geográficos. São José dos Campos, v. 264, 1995.

DAVIS, C., CÂMARA, G. Arquitetura de sistemas de informação geográfica. Introdução à ciência da geoinformação. São José dos Campos: INPE, 2001.

INSTITUTO BRASILEIRO DE GEOGRAFIA E ESTATÍSTICA - IBGE. Disponível em: https://cidades.ibge.gov.br/. Acesso em 10 de jun. 2018.

KERBAUY, M. T. "As Câmaras Municipais Brasileiras: Perfil de Carreira e Percepção Sobre o Processo Decisório Local". Opinião Pública, Campinas, vol. XI, n 2, p. 337-365, 2005.

LEI ORGÂNICA ATUALIZADA, com a incorporação de Emendas no ano 2004, sob a Direção da Mesa da Câmara, Dom Pedrito, 02 de abril de 1990.

MARBLE, D. Geografical Information Systems: an Overwiew. In: Pecora 9 Conference. Proceedings...Sioux Falls, v.1, p. 18-24, 1984.

MOURA, A.C.M. Contribuições metodológicas do Geoprocessamento à Geografia. Apostila do Curso de Geoprocessamento, IGC, UFMG, 2000.
NASCIMENTO, S.G.; MORAES, C.; HANKE, D.; ÁVILA, M.R.D., NUNES, O.M. (2018) - Plantas alimentícias não convencionais e agricultura familiar: limites e potencialidades de comercialização no município de Dom Pedrito-RS. Revista Agropampa, vol. 3, n. 2, p. 134-147

OLIVEIRA, L. P. S. (2006). O conceito de soberania perante a globalização. Revista CEJ, 80-88.

PIQUET, L.; ALMEIDA, M. H. "Definindo a Arena Política Local: Sistemas Partidários Municipais na Federação

Brasileira". Dados, Rio de Janeiro, vol. 51, $n^{\circ}$ 2, p. 403-442, 2008.

RAFFESTIN, C. Por uma geografia do poder. São Paulo: editora Ática, 1993.

RODRIGUES, P. H.; VILAÇA S. 1994. Subsídios para a utilização de geoprocessamento em sistemas municipais de informação. Revista de Administração Municipal. V. 41, n. 211, p. 51 - 60. ROSÉS, M. Conceptos para implementar aplicaciones georeferenciadas para Internet. Curso de Geomática. Codima. Barcelona. 2004.

SANTOS, M. A.; NASCIMENTO, J. A. S. DO. 1992. A inserção da variável ambiental no planejamento do território. Revista de Administração Pública, 26 (1): 6 - 12. VIEIRA, EVERTON; TAGLIANI, CARLOS RONEY. Criação de um banco de dados geográficos para o Município de Capão do Leão-RS. Anais... SIMPÓSIO BRASILEIRO DE SENSORIAMENTO REMOTO, v. 10, p. 1039-1046, 2001.

WEBER, E.; HASENACK, H. 1997. Uso de Sistemas de Informação Geográfica no Planejamento Urbano. Anais... In: VII 
Simpósio Brasileiro de Geografia Física

Aplicada. Curitiba. Anais, p. 117.

XAVIER-DA-SILVA, J. (2001) - Geopro-

cessamento para Análise Ambiental. Ed.

Rio de Janeiro. Rio de Janeiro, RJ, Brasil.

228p. 